\title{
KARAKTERISASI MINERALOGI MINERAL BERBASIS CU-Fe-S DENGAN SEM EDS DI DAERAH KELAPA KAMPIT, PULAU BELITUNG
}

\author{
Mineralogy Characterization of Cu-Fe-S Based Mineral Using SEM \\ EDS at Kelapa Kampit Area, Belitung
}

\author{
HARTAJA M. H. WICAKSONO ${ }^{{ }^{*}}$ dan ESTI HANDAYANI ${ }^{*}$ \\ 1 Pusat Sumber Daya Mineral Batubara dan Panas Bumi \\ Jalan Soekarno-Hatta No. 444 Bandung 40254 \\ Telp. (022 5202698; Fax. (022) 5226263 \\ e-mail: hartajawicaksono@gmail.com \\ 2 Puslitbang Teknologi Mineral dan Batubara \\ Jalan Jend. Sudirman 623 Bandung 40211 \\ Telp. (022) 6030483; Fax. (022) 6003373 \\ * Kontributor Utama
}

\begin{abstract}
ABSTRAK
Belitung merupakan bagian dari sabuk metalogeni mineralisasi timah Asia Tenggara. Mineralisasi timah di Pulau Belitung sangat erat kaitannya dengan keterdapatan tubuh batuan granit. Batuan granit yang terdapat di Pulau Belitung bukan merupakan tubuh batuan tunggal, melainkan terdiri dari beberapa formasi batuan dengan batuan granit utama pembawa timah adalah formasi Granit Tanjungpandan yang bertipe S. Mineral utama pembawa timah adalah kasiterit, dengan lokasi lapisan timah paling terkenal berada di daerah Kelapa Kampit yang disebut sebagai horison Nam Salu. Lapisan ini diketahui dipotong oleh urat polimetalik yang berisi pirit, siderit, pirhotit, kuarsa, kalkopirit, magnetit, arsenopirit, sphene dan kasiterit. Kehadiran mineralisasi bijih polimetalik yang memotong lapisan timah tersebut belum banyak diketahui dan dipublikasikan sehingga penelitian ini dilakukan untuk mengetahui karakteristik dari bijih tersebut, terutama unsur ikutan seperti tembaga dan besi. Metode yang digunakan, didasarkan pada pengamatan hasil pengujian mineragrafi, AAS dan SEM EDS. Hasil pengamatan mineragrafi menunjukkan sekuen paragenesa yang dimulai dari mineral kasiterit yang dipotong oleh sekuen mineral sulfida (kalkopirit-bornit-sfalerit-pirit-arsenopirit) yang terubah sebagian menjadi kovelit dan kalkolsit. Sekuen ini tertanam pada matriks gutit yang juga ditemukan dalam bentuk urat yang memotong tubuh matriks gutit dan mineral kasiterit yang menyebabkan mineral sulfida dengan basis unsur $\mathrm{Cu}$-Fe terubah menjadi mineral cuprit dan malasit. Hasil uji geokimia menggunakan AAS diketahui bahwa percontoh ini memiliki nilai kadar $\mathrm{Cu} 5,13 \%$;

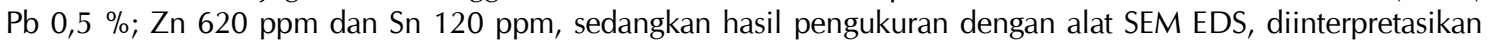
bahwa rumus empiris dari mineral sulfida diketahui rumus kalkopirit $\left(\mathrm{Cu}_{0,9} \mathrm{Fe}_{1,02} \mathrm{~S}_{2}\right)$, bornit $\left(\mathrm{Cu}_{4,1} \mathrm{Fe}_{1,29} \mathrm{~S}_{4}\right)$, sfalerit $\left(\left(\mathrm{Zn}_{0,64} \mathrm{Fe}_{0,2}\right) \mathrm{S}_{2}\right)$, pirit $\left(\mathrm{Fe}_{1,01} \mathrm{~S}_{2}\right)$, arsenopirit $\left(\mathrm{Fe}_{1,13} \mathrm{As0,62}\right)$, kovelit $\left(\mathrm{Cu}_{1,06} \mathrm{~S}\right)$ dan kalkolsit $\left(\mathrm{Cu}_{1,58 \mathrm{~S}}\right)$. Pada setiap mineral tersebut ditemukan residual unsur Sn pada setiap senyawanya meskipun dalam jumlah yang rendah. Hal ini dapat diinterpretasikan bahwa larutan pembentuk mineral-mineral tersebut terasimilasi atau sudah melakukan kontak dengan batuan pembawa unsur Sn. Selain itu, dapat diartikan juga bahwa mineralisasi polimetalik ini terbentuk setelah mineralisasi timah dan mungkin erat kaitannya dengan aktifitas magmatisme yang terjadi pada Kapur.
\end{abstract}

Kata kunci : Belitung, mineralisasi, timah, polimetalik, paragenesa 


\begin{abstract}
Belitung is part of the metallogenic belt of Southeast Asian tin mineralization. Tin mineralization on Belitung Island is very closely related to the presence of granite rock bodies. Granite rock found on Belitung Island itself is not a single rock body, but consists of several rock formations with the main granite rock carrying tin is a Stype Tanjungpandan Granite formation. The main mineral carrying tin is cassiterite, with the location of the most famous tin layer, found in the Kelapa Kampit area which is called the Nam Salu horizon. This layer is known to be cut by polymetallic veins containing pyrite, siderite, pyrrhotite, quartz, chalcopyrite, magnetite, arsenoprite, sphene and cassiterite. The presence of polymetallic ore mineralization which cuts through the tin layer is not well known and published, so this research was conducted to get a better understanding of ore characterization, mainly for associated elements such as copper and iron. The research method, based on observations from mineragraphy, AAS and SEM EDS testing. The result of mineragraphy observation showed paragenetic sequences starting from the cassiterite mineral which was cut by sulfide mineral sequences (chalcopyrite-bornite-sphalerite-pyrite-arsenopyrite) which were partially converted into covelite and chalcocite. This sequence was embedded in the goetite matrix, where goetite itself was also found in the form of veinlet which cut off the goetit matrix body and cassiterite mineral and caused sulfide minerals with the basis of Cu-Fe elements converted into cuprite and malachite minerals. The results of the geochemical test using AAS show that this sample has a value of $\mathrm{Cu}$ content of 5.13\%; Pb 0.5\%; Zn 620 ppm and Sn 120 ppm. Whereas from the measurement results using SEM EDS to find out the empirical formula of sulfide minerals, known

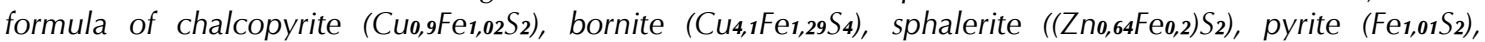
arsenopyrite $\left(\mathrm{Fe}_{1,13} \mathrm{As} \mathbf{0}_{62} \mathrm{~S}\right)$, covelit $\left(\mathrm{Cu}_{1,06 \mathrm{~S}}\right)$ and chalcolsite $\left(\mathrm{Cu}_{1,58} \mathrm{~S}\right)$. In each of these minerals, it is found residual Sn elements even though in small amounts. It can be interpreted that the solution forming the minerals was assimilated or has made contact with the rock carrying Sn element. It can also be interpreted that this polymetallic mineralization was formed after tin mineralization and may be closely related to the activity of magmatism that occurred in Cretaceous.
\end{abstract}

Keywords : Belitung, mineralization, tin, polymetallic, paragenetic

\section{PENDAHULUAN}

Perkembangan teknologi yang pesat dewasa ini membawa perubahan pada segala aspek kegiatan perindustrian, tidak terkecuali menyentuh pada bidang pertambangan khususnya kegiatan eksplorasi. Kegiatan eksplorasi tidak hanya dituntut untuk menemukan sebuah endapan bernilai ekonomis, tetapi juga bisa memberikan informasi yang lebih rinci mengenai karakterisasi bijih mineral logam yang terkandung pada endapan tersebut. Regulasi pemerintah Indonesia saat ini mewajibkan untuk meningkatkan nilai tambah dari endapan bijih yang ada, dengan cara melakukan pengolahan awal agar mineral-mineral ikutan dari komoditas mineral utama tidak terbuang percuma. Karena itu, informasi mengenai karakterisasi bijih mineral logam sangat penting. Hal ini dikaitkan dengan pemilihan teknologi tepat guna dalam pengolahan dan pemisahan dari mineral-mineral tersebut sehingga didapatkan hasil yang optimal khususnya di daerah-daerah tambang skala kecil yang kegiatan pengolahannya masih dilakukan dengan cara sederhana, sehingga potensi terbuangnya mineral-mineral ikutan yang bernilai ekonomis sangat besar. Kabupaten Belitung Timur merupakan salah satu produsen utama bahan galian tambang logam timah (Natasia $d k k ., 2016$ ). Di beberapa tempat, komoditas timah ini tidak berdiri sendiri melainkan dengan mineral ikutan lainnya seperti tembaga dan besi, salah satunya di daerah Kelapa Kampit.

Di sekitar lokasi tambang Kelapa Kampit, tepatnya di kaki bukit Kelapa Kampit sebelah utara, masih berlangsung kegiatan tambang rakyat dengan cara membuat lubang vertikal ke dalam bukit atau membuat penambangan di sekitar bukit dengan target timah sedimen atau primer. Kehadiran mineralisasi bijih polimetalik yang memotong lapisan timah belum banyak diketahui dan dipublikasikan perihal karakteristiknya. Penelitian ini dilakukan untuk mengetahui karakteristik mineral berbasis Cu-Fe-S menggunakan SEM EDS (Miler, Curk dan Mirtič, 2009; Batista $d k k ., 2018$; Astuti $d k k ., 2020)$ dengan harapan memberikan gambaran mengenai paragenesa mineral dan karakteristik mineralisasi bijih polimetalik di daerah Belitung, khususnya di Kelapa Kampit. 


\section{GEOLOGI REGIONAL DAERAH PENELITAN}

Baharuddin dan Sidarto (1995) di dalam Peta Geologi Lembar Belitung (Gambar 1) menyebutkan bahwa geologi Pulau Belitung tersusun oleh batuan sedimen klastik yang mengalami proses metamorfik dan terlipat berumur Permo-Karbon dan terdiri dari Formasi Kelapakampit, Formasi Tajam, serta Formasi Siantu yang berupa batuan vulkanik. Formasi-formasi tersebut diterobos oleh Granit Tanjungpandan yang bertipe $S$ dan berumur Trias Akhir (Schwartz, 1992). Granit tersebut merupakan granit utama pembawa bijih timah. Selain itu, formasi-formasi tersebut juga diterobos oleh Adamelit Baginda dengan afinitas magma kalk-alkali, bertipe I, berasosiasi dengan aktifitas subduksi dan memiliki kadar timah yang sangat rendah (Ikhsan dan Titisari, 2016). Selain 2 jenis granit tersebut, di pulau Belitung juga terdapat tubuh intrusi granit lain yaitu granit Kelumpang yang ditemukan di Pantai Balok. Granit ini merupakan granit tipe I. Pada bagian granit Biotit, ditemukan adanya mineralisasi kasiterit sedangkan pada granit hornblenda tidak ditemukan mineralisasi (Aryanto $d k k ., 2016$ ). Selain granit-granit tersebut juga terdapat formasi Granodiorit Burung Mandi, Granit Batubesi dan Granit Tanjung Pandan.

\section{MINERALISASI REGIONAL DAERAH PENELITIAN}

Pembahasan mengenai mineralisasi timah di Pulau Belitung sudah dimulai sejak tahun 1937. Teori yang berkembang menyebutkan bahwa mineralisasi terjadi pada bagian yang sangat dalam, pada kontak batuan metamorfisme dari 1 tubuh granit besar dengan umur mineralisasi timah setelah Trias (Jones $d k k ., 1977)$. Disebutkan juga bahwa komoditas utama timah dihasilkan dari endapan letakan (placer) yang berasal dari endapan urat timah primer dalam batuan granit. Di daerah ini terdapat 2 tubuh granit yang berbeda, yaitu granit yang lebih tua dari batuan sedimen dan tidak berasosiasi dengan timah serta granit berumur Kapur yang terbentuk setelah batuan sedimen dan berasosiasi dengan mineralisasi timah yang terjadi sekitar Pliosen. Endapan timah utama ditemukan pada lapisan di sekitar lembah yang disebut lapisan "Kaksa". Teori lain menyebutkan mineralisasi terjadi di dalam batuan sedimen yang berumur Permo-Carbon dengan struktur perlipatan, dekat dengan intrusi granit berumur Mesozoikum. Endapan kasiterit paling penting berada pada lapisan yang sejajar dengan perlapisan, terutama pada kontak batuserpih dan batupasir atau radiolarit yang berasosiasi dengan magnetit (Sutarto $d k k ., 2017)$.

Di daerah Tebrong, timur Pulau Belitung, memiliki geologi berupa batuan granit plutonik dan metasedimen yang termineralisasi Sn dengan tingkat rendah. Mineralisasi ini berupa urat sub-vertikal kuarsa-turmalin-kasiterit yang di atasnya terendapkan endapan letakan kasiterit "Kaksa" berumur Kuarter (Johari, 1987). Endapan letakan "Kaksa" tersebut merupakan hasil dari proses denudasional yang sangat lama pada masa Tersier dalam kondisi basah sehingga proses pelapukan kimia menjadi intensif. Sifat kimia pelapukan granit di Belitung tersebut menyebabkan perubahan total pada mineral feldspar dan mineral berbasis Fe-Mg serta meninggalkan residu kuarsa dan beberapa mineral aksesori. Di daerah Parit Tebu, karakteristik endapan timah berupa mineralisasi timah primer pada urat kuarsa yang memotong batuan sedimen arenit kuarsa dan meta-batulempung dan berasosiasi dengan mineral realgar, molibdenit, pirit, sfalerit dan galena. Sekuen batuan sedimen tersebut diintrusi oleh aplit (Pardiarto, 2016).

Di daerah Batubesi, cebakan bijih berupa bijih besi primer tipe skarn iron tin polymetallic dengan mineral utama adalah magnetit dan mineral ikutan radioaktif berupa monasit dan zirkon serta mineral ikutan lainnya adalah hematit, ilmenit, kasiterit, dan rutil (Ngadenin $d k k ., 2017)$.

Di daerah Kelapa Kampit, mineralisasi timah sejajar dengan perlapisan batuan sedimen dan vulkanik berumur Karbon-Perm yang disebut horison Nam Salu. Horison ini merupakan lapisan timah paling kaya di Asia Tenggara dan diintrusi oleh batuan granitoid berumur Trias sebagai sumber utama fluida magmatik pembawa timah (Schwartz, 1992). Mineralisasi primer timah di daerah Kelapa Kampit merupakan urat hidrotermal dengan kemiringan yang curam berarah utara dengan jurus $\mathrm{N} 110^{\circ} \mathrm{E}$ dan berhubungan dengan pergerakan granit pada akhir Trias. 


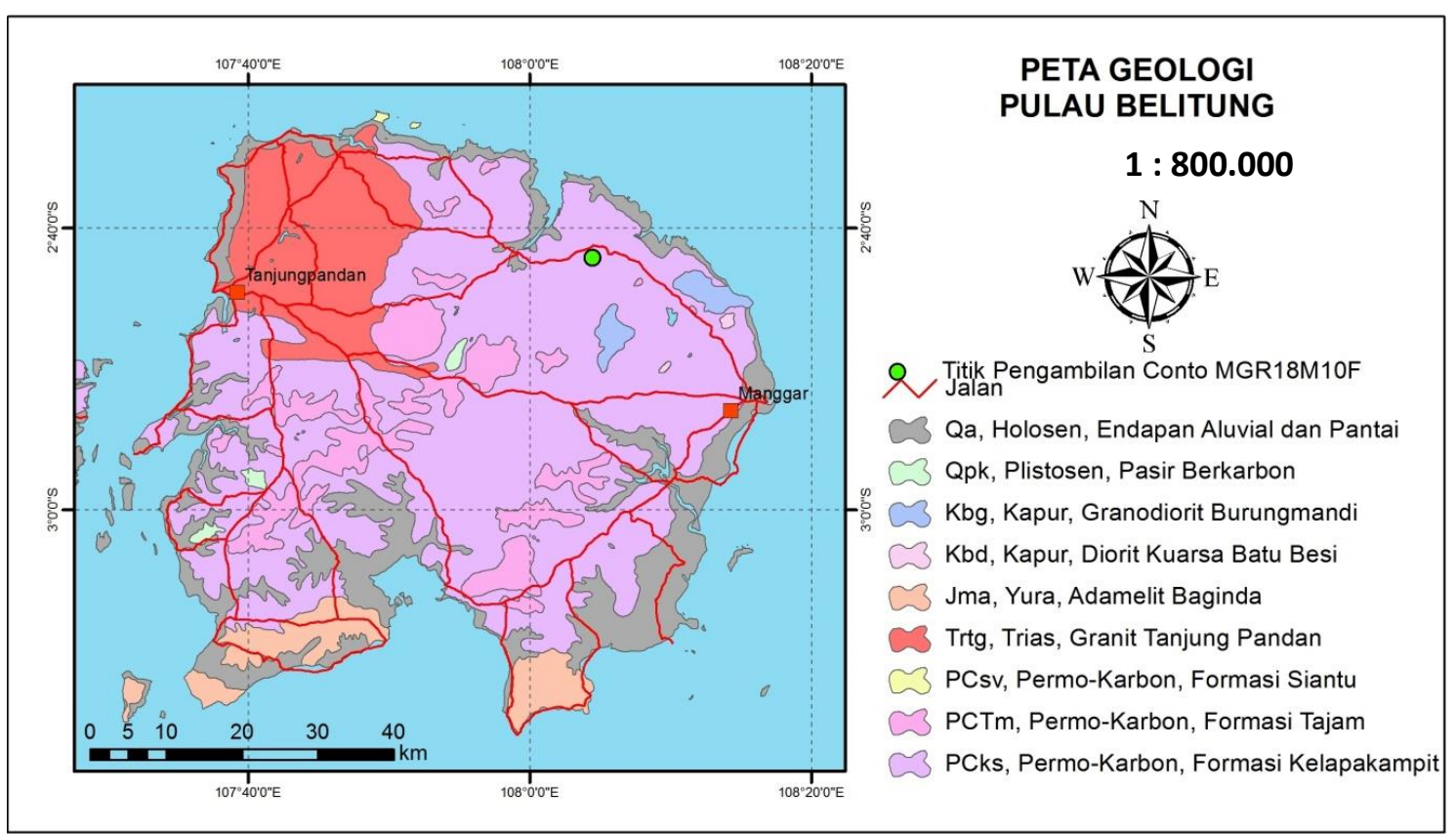

Gambar 1. Peta geologi dan lokasi penelitian (Baharuddin dan Sidarto, 1995)

\section{METODE}

Metode yang digunakan dalam penelitian ini didasarkan pada pengamatan dari satu percontoh apungan/float (Gambar 2) yang mengalami mineralisasi tembaga yang ditandai dengan kehadiran mineral malasit di sekitar hematit (MGR18M010F). Percontoh ini diambil dari daerah Kelapa Kampit (Gambar 1). Metode analisis yang dilakukan pada percontoh ini berupa pengujian mineragrafi, geokimia AAS (Atomic Absorption Spectrometry) dan analisis SEM-EDS (Scanning Electron MicroscopeEnergy Dispersive $X$-ray). Analisis mineragrafi dilakukan dengan mengamati sayatan poles dari percontoh batuan di bawah mikroskop pantul menggunakan Mikroskop Zeiss Axio Imager A2m untuk mengetahui kandungan mineral logam pada batuan termineralisasi serta paragenesanya. Pengamatan mineragrafi ini dilakukan sebagai langkah awal untuk mendeteksi keberadaan mineral logam dari percontoh tersebut. Analisis ini dilakukan di laboratorium Pusat Sumber Daya Mineral Batubara dan Panas Bumi (PSDMBP) serta dilanjutkan di laboratorium Pusat Penelitian dan PengembanganTeknologi Mineral dan Batubara (Puslitbang tekMIRA).

Analisis geokimia dilakukan dengan melakukan uji AAS terhadap unsur $\mathrm{Cu}, \mathrm{Pb}, \mathrm{Zn}$ dan Fe pada batuan termineralisasi, yang dilakukan di laboratorium PSDMBP. Analisis SEM EDS dilakukan di laboratorium Puslitbang tekMIRA menggunakan alat SEM JEOL JSM 6360LA dengan fasilitas analisis komposisi kimia menggunakan sinar X (Hafner, 2013). Analisis komposisi kimia dari SEM EDS meliputi unsur $\mathrm{Cu}, \mathrm{Zn}, \mathrm{Fe}, \mathrm{Ag}, \mathrm{As}, \mathrm{Sn}$ dan S. Analisis SEM EDS ini meliputi pengukuran pada titik pada sayatan tertentu. Analisis SEM EDS ini dilakukan pada percontoh hasil preparasi sayatan poles yang telah dilakukan pengamatan mineragrafi. Dalam penelitian ini, pengukuran dan penghitungan normalisasi rumus kimia (Yahya, 2016), hanya dilakukan untuk mineral-mineral sulfida dan terbatas untuk 5 hingga 7 kali titik pengukuran untuk setiap mineral sulfida.

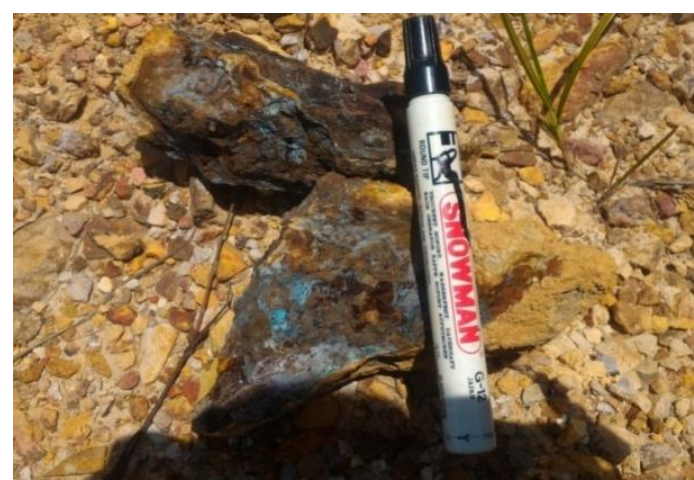

Gambar 2. Foto percontoh setangan/hand specimen batuan MGR18M010F 


\section{HASIL DAN PEMBAHASAN}

Hasil analisis mineragrafi menunjukkan percontoh batuan mengandung mineralmineral sulfida tembaga dan besi seperti pirit, kalkopirit, bornit, kovelit, kalkosit, arsenopirit dan sfalerit yang tertanam pada masa dasar gutit dan memotong mineral pembawa timah yaitu kasiterit. Mineral-mineral sulfida tersebut mengalami proses oksidasi sehingga terubah menjadi malasit, cuprit dan gutit. Yang cukup menarik dari hasil pengamatan mineragrafi diketahui bahwa mineral-mineral seperti kalkopirit, bornit, sfalerit, pirit dan arsenopirit menunjukkan tekstur rimming dan terubah menjadi mineral kovelit dan atau kalkosit. Selain ditemukan sebagai matriks, gutit juga ditemukan sebagai urat tipis yang memotong tubuh matriks dan kasiterit. Karakteristik optik masing- masing mineral bijih yang terkandung dalam percontoh adalah sebagai berikut

- Kalkopirit, berwarna kuning, berukuran sangat halus $(<0,05 \mathrm{~mm})$, bentuk subhedral hingga anhedral, bersifat anisotrop lemah, di beberapa tempat nampak tumbuh bersama dengan bornit dan sebagian besar telah digantikan oleh kovelit serta kalkosit (Gambar 3a), dan tersebar tidak merata/sangat jarang pada massa dasar berupa gutit. Selain itu ditemukan pada sfalerit sebagai "chalcopyrite disease" (inklusi mineral kalkopirit dalam mineral sfalerit) (Barton, 1978 dalam Kant $d k k ., 2015)$.

- Bornit, berwarna ungu hingga jingga/ keunguan, berbentuk tidak beraturan, bersifat anisotrop lemah, terdapat tumbuh bersama dengan kalkopirit dan kemudian digantikan oleh kalkosit (Gambar 3a), dan tersebar tidak merata/sangat jarang pada massa dasar berupa gutit.

- Kovelit, berwarna biru, hadir dengan bentuk tidak beraturan, mempunyai refleksi ganda, mempunyai sifat anisotrop kuat dengan warna coklat kemerahan-oranye, terlihat menggantikan pirit (Gambar 3d), kalkopirit (Gambar 3a), dan digantikan oleh kalkosit, dan tersebar tidak merata pada massa dasar berupa gutit (Gambar 3e).

- Kalkosit, berwarna putih kebiruan, hadir dengan bentuk yang tidak beraturan, mempunyai sifat yang isotrop, terlihat menggantikan kalkopirit dan kovelit (Gambar 3a), tersebar tidak merata pada massa dasar berupa gutit, maupun mengisi celah retakan pada kasiterit.

- Pirit, berwarna putih kekuningan, berukuran sangat halus $(<0,05 \mathrm{~mm})$ hingga halus $( \pm$ 0,14 mm), bentuk subhedral hingga anhedral dengan relief tinggi, bersifat anisotrop lemah atau isotrop, sebagian nampak retak-retak dan digantikan oleh kovelit serta kalkosit (Gambar 3d), tersebar tidak merata pada massa dasar berupa gutit.

- Arsenopirit, berwarna krem kekuningan, bentuk euhedral-subhedral, bersifat anisotrop kuat, sebagian menunjukkan adanya kembaran, dijumpai tersebar pada massa dasar gutit (Gambar 3e).

- Gutit, berwarna abu-abu, memiliki refleksi dalam merah kecoklatan, anisotrop dengan refleksi dalam berwarna coklat, dijumpai tersebar sebagai massa dasar dan juga dalam bentuk urat dengan tekstur koloform (Gambar 3e).

- Kuprit, berwarna abu-abu kebiruankemerahan, bentuk tidak beraturan, bersifat anisotrop dengan refleksi dalam berwarna merah, dijumpai tersebar pada massa dasar gutir serta mengisi retakan (Gambar 3e).

- Malakit, berwarna abu-abu kehijauan, bentuk tidak beraturan, bersifat anisotrop dengan refleksi dalam berwarna hijau cerah, dijumpai tersebar pada massa dasar gutit serta mengisi retakan (Gambar 3e).

- Sfalerit, berwarna abu-abu, bentuk butiran euhedral, bersifat isotrop dengan refleksi dalam berwarna coklat, dijumpai dikelilingi (rimmed) oleh kalkosit, dan mengandung inklusi kalkopirit (chalcopyrite disease) (Gambar 3b), butiran sfalerit tersebar tidak merata dalam massa dasar gutit. 

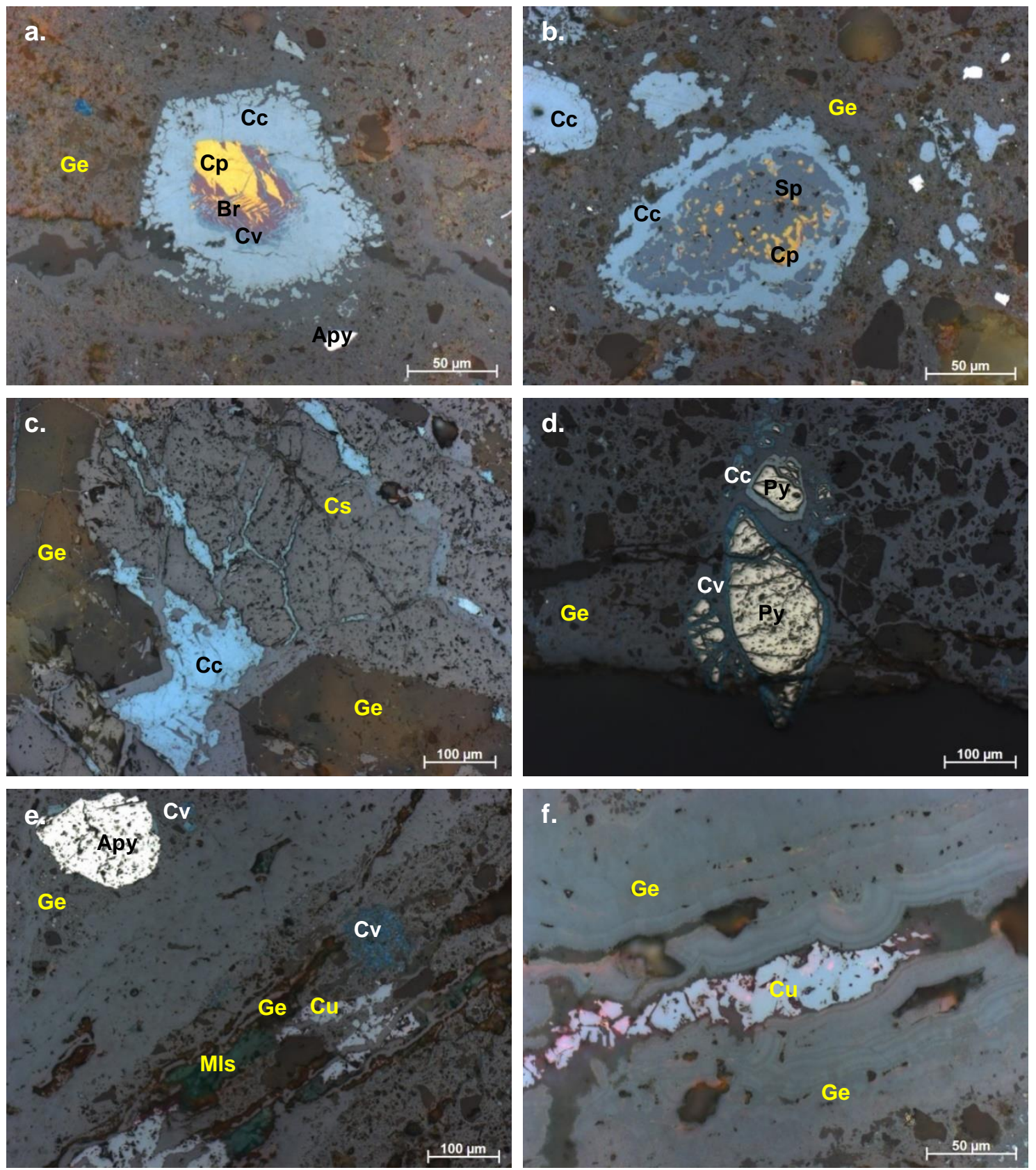

Keterangan:
Apy = Arsenopirit;
$\mathrm{Cs}=$ Sfalerit;
$\begin{array}{ll}\text { Py }=\text { Pirit; } & \mathrm{Br}=\text { Bornit; } \\ \mathrm{CV}=\text { Kovelit; } & \mathrm{Sp}=\text { Sfalerit; }\end{array}$
$\mathrm{Cp}=$ Kalkopirit;
$\mathrm{Cc}=$ Kalkosit;
$\mathrm{Ge}=$ Gutit:
Mls $=$ Malasit;

$\mathrm{Cu}=$ Cuprit

Gambar 3. Foto mikrograf percontoh MGR18M010F

(a) kalkopirit dan bornit yang tumbuh bersama dan terubah menjadi kalkosit dan kovelit pada bagian luar (rimming) dan tertanam pada massa gutit;

(b) sfalerit dengan "chalcopyrite disease" yang terubah menjadi kalkosit;

(c) retakan pada kasiterit yang terisi oleh kalkosit;

(d) pirit yang terubah menjadi kalkosit dan kovelit;

(e) matriks gutit yang terpotong oleh urat gutit- cuprit-malasit;

(f) urat gutit yang memperlihatkan tekstur krustiform disertai cuprit yang mengisi celah antar gutit. 

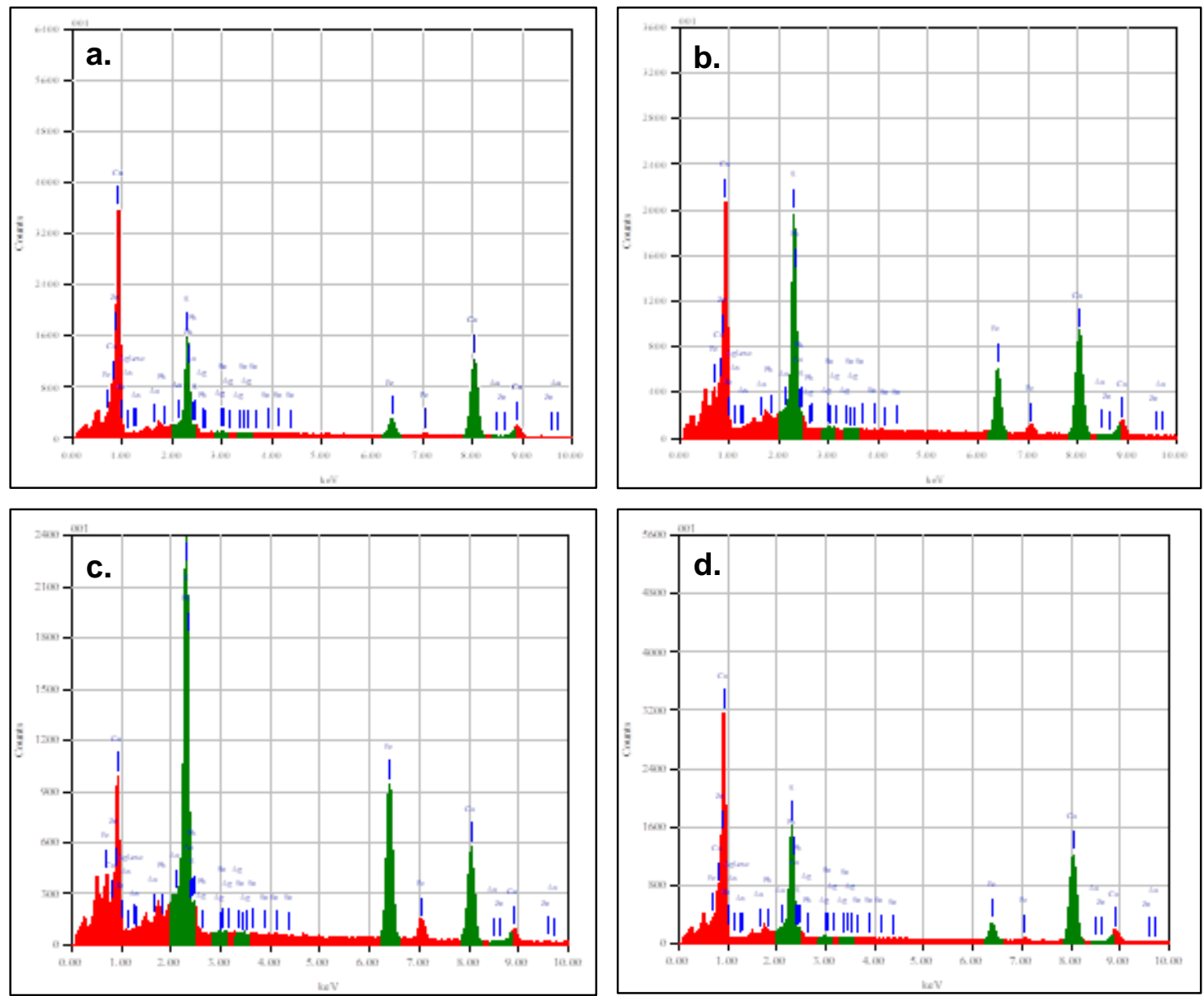

Gambar 4. Grafik hasil pengukuran SEM-EDS mineral (a) kalkosit; (b) bornit; (c) kalkopirit; (d) kovelit.

\section{HASIL PENGUKURAN SEM EDS}

Hasil pengukuran SEM-EDS dari mineral dengan komponen unsur $\mathrm{Cu}$ menunjukkan pola-pola yang hampir sama tetapi dengan jumlah komponen unsur $\mathrm{Cu}, \mathrm{Fe}, \mathrm{S}, \mathrm{Zn}, \mathrm{As}, \mathrm{Ag}$ dan Sn yang berbeda-beda.

Mineral-mineral tersebut menunjukkan karaktersitik unsur : $\mathrm{Cu}(\mathrm{K} \alpha$ 8,040 keV), Fe (Ka $6,398 \mathrm{keV}), \mathrm{S}(\mathrm{K} \alpha 2,307 \mathrm{keV}), \mathrm{Zn}(\mathrm{K} \alpha$ 8,630 $\mathrm{keV}), \mathrm{Ag}(\mathrm{L} \alpha 2,983 \mathrm{keV})$ dan Sn (La 3,442 keV). Data tersebut menunjukkan bahwa unsurunsur seperti $\mathrm{Cu}$, Fe, S dan $\mathrm{Zn}$ berada pada kulit atom $\mathrm{K}$ sedangkan unsur $\mathrm{Ag}$ dan $\mathrm{Sn}$ berada pada kulit atom $\mathrm{L}$.

Grafik pengukuran untuk mineral kalkosit (Gambar 4a) menunjukkan pengukuran peak tertinggi pada unsur $\mathrm{Cu}$ yang diikuti oleh unsur $\mathrm{S}$, sedangkan unsur-unsur lain $\mathrm{Ag}, \mathrm{Au}, \mathrm{Sn}$ dan Fe tidak menunjukkan jumlah yang signifikan, hal ini juga terlihat untuk grafik pengukuran pada mineral kovelit (Gambar 4d). Grafik pengkuran mineral bornit (Gambar 4b), menunjukkan peak tertinggi pada grafik terlihat untuk unsur $\mathrm{Cu}$ dan $\mathrm{S}$ lalu diikuti unsur Fe, sedangkan untuk Ag, Au, Sn dan Zn tidak menunjukkan jumlah yang signifikan. Sedangkan untuk mineral kalkopirit (Gambar 4c) terjadi anomali peak untuk unsur S, sedangkan untuk unsur $\mathrm{Cu}$ dan Fe masih menunjukkan peak yang sedang.

\section{KIMIA MINERAL}

Proses mineralisasi akan memberikan variasi kandungan unsur yang berbeda untuk setiap mineral yang terkandung dalam batuan. Hasil pengukuran dengan metode AAS pada batuan menunjukkan nilai kadar $\mathrm{Cu} 5,13 \%$; Pb 0,5 \%; Zn 620 ppm dan Sn 120 ppm. Pengujian SEM EDS dilakukan dengan melakukan pengukuran hanya pada mineral bijih dengan basis sulfida. Hasil rata-rata pengukuran dan perhitungan 
normalisasi untuk setiap mineral sulfida disajikan pada Tabel 1 .

Berdasarkan hasil pengukuran geokimia, penentuan rumus empiris pada mineral arsenopirit, bornit, sfalerit dan kalkosit menunjukkan hasil yang cukup berbeda dengan rumus molekul, sedangkan mineral sulfida lain seperti kalkopirit, kovelit, dan pirit menujukkan hasil yang sedikit berbeda namun tidak signifikan, sehingga dapat dianggap diabaikan.

Hasil perhitungan rumus empiris tersebut kemudian dibandingkan dengan rumus molekul dari mineral-mineral sulfida. Hasil perbandingan tersebut dapat dilihat pada Tabel 2.

Selain pengukuran dan perhitungan rumus empiris pada masing-masing mineral sulfida, dilakukan juga pengukuran untuk mengetahui pola kenaikan dan penurunan nilai masingmasing unsur pada beberapa sayatan mineral sulfida. Pada penelitian ini, pengukuran dilakukan pada mineral bornit dan sfalerit yang sebagian terubah menjadi mineral kalkosit dan kovelit. Titik pengukuran dan hasil pengukuran dapat dilihat pada Gambar 5.

Tabel 1. Hasil pengukuran dan perhitungan normalisasi dari mineral sulfida

\begin{tabular}{|c|c|c|c|c|c|c|c|}
\hline $\begin{array}{c}\text { Rata - rata } \\
\text { pengukuran } \\
\text { (At } \%)\end{array}$ & Arsenopirit & Bornit & Kalkosit & Kalkopirit & Kovelit & Pirit & Sfalerit \\
\hline $\mathrm{S}$ & 22,31 & 27,71 & 22,41 & 35,83 & 30,46 & 51,76 & 35,39 \\
\hline $\mathrm{Fe}$ & 43,89 & 15,56 & 6,89 & 31,94 & 5,70 & 45,65 & 12,46 \\
\hline $\mathrm{Cu}$ & 1,61 & 56,25 & 70,31 & 31,78 & 63,17 & 2,37 & 5,48 \\
\hline $\mathrm{Zn}$ & 0,02 & 0,22 & 0,17 & 0,25 & 0,30 & 0,07 & 46,51 \\
\hline As & 32,13 & 0,09 & 0,01 & 0,17 & 0,03 & 0,03 & 0,02 \\
\hline $\mathrm{Ag}$ & 0,01 & 0,11 & 0,08 & 0,08 & 0,05 & 0,03 & 0,05 \\
\hline $\mathrm{Sn}$ & 0,04 & 0,05 & 0,15 & 0,13 & 0,29 & 0,09 & 0,09 \\
\hline \multicolumn{8}{|l|}{$\begin{array}{c}\text { rata - rata } \\
\text { At. \%/el.At }\end{array}$} \\
\hline $\mathrm{S}$ & 0,6956 & 0,8643 & 0,6989 & 1,1173 & 0,9499 & 1,6142 & 1,1037 \\
\hline $\mathrm{Fe}$ & 0,7848 & 0,2782 & 0,1231 & 0,5711 & 0,1020 & 0,8161 & 0,2227 \\
\hline $\mathrm{Cu}$ & 0,0253 & 0,8852 & 1,1064 & 0,5000 & 0,9941 & 0,0373 & 0,0862 \\
\hline $\mathrm{Zn}$ & 0,0002 & 0,0033 & 0,0026 & 0,0037 & 0,0046 & 0,0011 & 0,7113 \\
\hline As & 0,4288 & 0,0012 & 0,0001 & 0,0022 & 0,0003 & 0,0003 & 0,0003 \\
\hline $\mathrm{Ag}$ & 0,0001 & 0,0010 & 0,0007 & 0,0007 & 0,0005 & 0,0003 & 0,0004 \\
\hline Sn & 0,0004 & 0,0004 & 0,0013 & 0,0011 & 0,0024 & 0,0008 & 0,0007 \\
\hline \multicolumn{8}{|l|}{$\begin{array}{l}\text { Normalisasi } \\
\text { terhadap S }\end{array}$} \\
\hline $\mathrm{S}$ & 1,00 & 4,00 & 2,00 & 2,00 & 1,00 & 2,00 & 1,00 \\
\hline $\mathrm{Fe}$ & 1,13 & 1,29 & 1,02 & 1,02 & 0,08 & 1,01 & 0,20 \\
\hline $\mathrm{Cu}$ & 0,04 & 4,10 & 0,90 & 0,90 & 1,29 & 0,05 & 0,08 \\
\hline $\mathrm{Zn}$ & 0,00 & 0,02 & 0,01 & 0,01 & 0,00 & 0,00 & 0,64 \\
\hline As & 0,62 & 0,01 & 0,00 & 0,00 & 0,00 & 0,00 & 0,00 \\
\hline $\mathrm{Ag}$ & 0,00 & 0,00 & 0,00 & 0,00 & 0,00 & 0,00 & 0,00 \\
\hline \multirow[t]{2}{*}{ Sn } & 0,00 & 0,00 & 0,00 & 0,00 & 0,00 & 0,00 & 0,00 \\
\hline & $\mathrm{Fe}_{1,13} \mathrm{As}_{0,62 \mathrm{~S}} \mathrm{~S}$ & $\mathrm{Cu}_{4,1} \mathrm{Fe}_{1,29} \mathrm{~S}_{4}$ & Cu1,58S & $\mathrm{Cu}_{0,9} \mathrm{Fe}_{1,02} \mathrm{~S}_{2}$ & $\mathrm{Cu}_{1,06 \mathrm{~S}}$ & $\mathrm{Fe}_{1,01} \mathrm{~S}_{2}$ & $\left(Z_{0,64} F_{0,2}\right) S_{2}$ \\
\hline
\end{tabular}

Tabel 2. Hasil perbandingan rumus molekul dan empiris dari mineral sulfida

\begin{tabular}{|c|c|c|}
\hline Mineral & Rumus Molekul & Rumus Empiris \\
\hline Arsenopirit & FeAsS & $\mathrm{Fe}_{1, \mathbf{1 3}} \mathrm{Ass}_{\mathbf{0}, \mathbf{6 2} \mathrm{S}}$ \\
\hline Bornit & $\mathrm{Cu}_{5} \mathrm{FeS}_{4}$ & $\mathrm{Cu}_{4,1} \mathrm{Fe}_{1,29 \mathrm{~S}_{4}}$ \\
\hline Kalkosit & $\mathrm{Cu}_{2} \mathrm{~S}$ & Cu1,58S \\
\hline Kalkopirit & $\mathrm{CuFeS}_{2}$ & $\mathrm{Cu}_{0,9} \mathrm{Fe}_{1,02} \mathrm{~S}_{2}$ \\
\hline Kovelit & $\mathrm{CuS}$ & $\mathrm{Cu}_{1,06} \mathrm{~S}$ \\
\hline Pirit & $\mathrm{FeS}_{2}$ & $\mathrm{Fe}_{\mathbf{1}, \mathbf{0 1}} \mathrm{S}_{\mathbf{2}}$ \\
\hline Sfalerit & $(\mathrm{Zn}, \mathrm{Fe}) \mathrm{S}_{2}$ & $\left(\mathrm{Zn}_{0,64} \mathrm{Fe}_{0,2}\right) \mathrm{S}_{2}$ \\
\hline
\end{tabular}



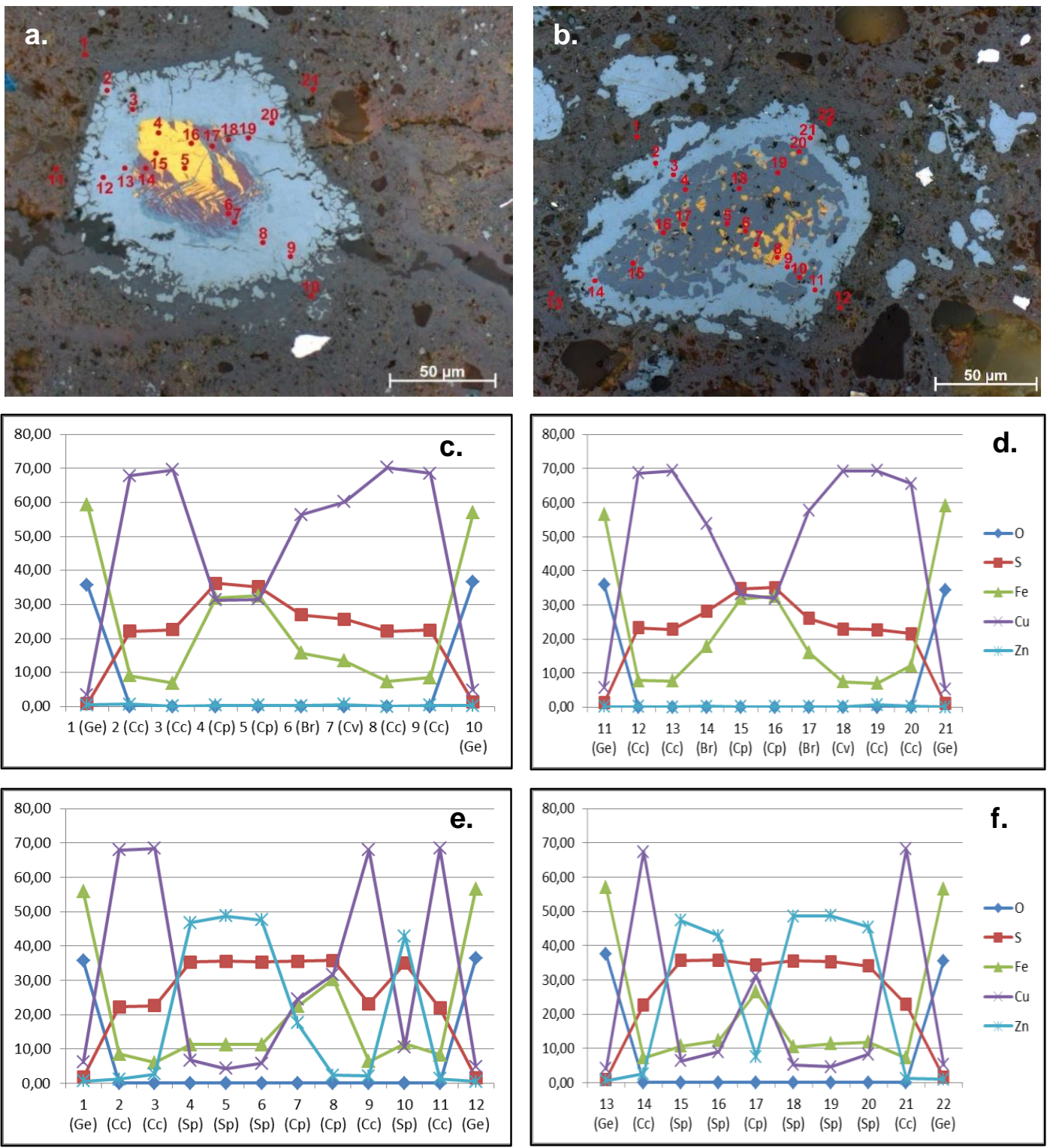

Keterangan:

$\mathrm{Br}=$ Bornit; $\quad \mathrm{Cp}=$ Kalkopirit; $\quad \mathrm{Cc}=$ Kalkosit;

$\mathrm{Cv}=$ Kovelit;

$\mathrm{Sp}=$ Sfalerit;

$\mathrm{Ge}=$ Gutit

Gambar 5. (a) Titik pengukuran SEM-EDS pada mineral kalkopirit-bornit-kovelit-kalkosit-gutit

(b) Titik pengukuran SEM-EDS pada mineral sfalerit-kalkosit-gutit

(c) Grafik hasil pengukuran At.\% untuk titik 1 - 10 mineral kalkopirit-bornit-kovelit-kalkosit-gutit

(d) Grafik hasil pengukuran At.\% untuk titik $11-21$ mineral kalkopirit-bornit-kovelit-kalkosit-gutit

(e) Grafik hasil pengukuran At.\% untuk titik 1 - 12 mineral sfalerit-kalkosit-gutit (f) Grafik hasil pengukuran At. \% untuk titik 13 - 22 mineral sfalerit-kalkosit-gutit

Grafik hasil pengukuran pada sayatan bornitkalkopirit (Gambar 5c dan 5d) memperlihatkan pola yang sama. Nilai unsur $\mathrm{Cu}$ berbanding terbalik dengan nilai unsur Fe. Semakin ke arah luar atau menjauh dari inti, terjadi penurunan konsentrasi unsur Fe dengan diikuti kenaikan unsur $\mathrm{Cu}$. Unsur Fe mengalami sedikit trend kenaikan ketika mendekati massa dasar gutit, sedangkan unsur S mengalami trend penurunan semakin ke arah luar. Pada bagian mineral gutit, terjadi kenaikan signifikan pada unsur Fe dan $\mathrm{O}$, serta penurunan signifikan pada unsur $\mathrm{S}$ dan $\mathrm{Cu}$.

Grafik hasil pengukuran pada sayatan Sfalerit (Gambar 5e dan 5f) memperlihatkan sedikit gambaran yang berbeda. Unsur-unsur Zn, Fe dan Cu memiliki pola yang relatif stabil dengan penurunan yang tidak begitu tajam ke arah luar 
(mendekati gutit), namun memiliki pola yang sama pada unsur $\mathrm{S}$ yang memiliki trend penurunan ke arah luar.

\section{DISKUSI}

Hasil pengujian mineragrafi menunjukkan mineral kasiterit dipotong oleh sekuen mineral sulfida (kalkopirit-bornit-sfalerit-pirit-arsenopirit) yang terubah sebagian menjadi kovelit dan kalkosit (Liu, Chen dan Yang, 2020). Sekuen ini tertanam pada matriks gutit yang juga ditemukan dalam bentuk urat serta memotong tubuh matriks gutit dan kasiterit sehingga menyebabkan mineral sulfida dengan basis unsur Cu-Fe terubah menjadi mineral kuprit dan malasit yang merupakan mineral dengan basis oksida. Sekuen paragenesa dari mineral bijih ini secara garis besar dapat dibagi menjadi 2 tahapan utama yaitu tahap sulfida yang terubah menjadi tahap oksida (Gambar 6). Garis tegas pada Gambar 6 merupakan sekuen pembentukan mineral sedangkan garis putusputus menunjukkan sekuen pembentukan mineral yang diperkirakan.

Perbedaan rumus empiris untuk mineral arsenopirit terhadap mineral empiris terletak pada jumlah molekul unsur As dan Fe. Rumus molekul As memiliki jumlah molekul 2 sedangkan dari perhitungan rumus empiris memperlihatkan molekul berjumlah 0,62, sehingga terjadi pengurangan dari rumus molekulnya. Hal yang berbeda terjadi pada unsur Fe karena terjadi penambahan jumlah molekul dari rumus molekul yang berjumlah 1 menjadi 1,13. Perbedaan rumus juga terjadi pada mineral bornit. Pengurangan pada unsur Cu menjadi 4,1 yang seharusnya berjumlah 5 . Selain itu, terjadi penambahan pada unsur Fe dari seharusnya berjumlah 1 menjadi 1,29.
Pada kalkosit terjadi perbedaan pada unsur $\mathrm{Cu}$ yang seharusnya berjumlah 2 berkurang menjadi 1,58, sedangkan pada sfalerit terjadi pengurangan pada jumlah rasio unsur Zn-Fe, dari yang seharusnya berjumlah 1 menjadi 0,84. Perubahan ini terjadi kemungkinan karena terdistribusinya molekul unsur tersebut ke mineral lain, atau sebaliknya, terjadi penambahan molekul unsur tertentu misal unsur Fe ke dalam mineral, sehingga rasio konsentrasi antar unsur dari mineral menjadi sedikit berubah. Hal ini dapat dilihat pada hasil pengukuran untuk mengetahui pola kenaikan dan penurunan unsur dari sayatan bornitkalkopirit (Gambar 5a) dan sfalerit (Gambar 5b).

Pada mineral bornit dan kalkopirit terjadi pelepasan unsur Fe dan S ketika mineral bornit atau kalkopirit berubah menjadi kovelit atau kalkosit yang disertai dengan meningkatnya konsentrasi $\mathrm{Cu}$. Pada sayatan ini mineral berbasis $\mathrm{Cu}$-Fe-S menunjukkan tekstur eksolusi yang ditunjukkan dengan paragenesa mineral dari kalkopirit-bornit-kovelit-kalkosit (Liu, Chen dan Yang, 2020).

Kehadiran mineral kalkopirit sebagai "chalcopyrite disease" dalam mineral sfalerit memperlihatkan pola yang sama dengan mineral kalkopirit pada sayatan bornit-kalkopirit namun dengan adanya konsentrasi unsur Zn yang relatif lebih tinggi. Hal ini menunjukkan terjadinya pelepasan unsur $\mathrm{Zn}$ dan $\mathrm{S}$ ketika mineral sfalerit berubah menjadi kalkosit yang tentunya disertai dengan meningkatnya konsentrasi Cu. Kenampakan "chalcopyrite disease" pada mineral sfalerit ini juga kemungkinan disebabkan oleh pengkayaan yang terjadi pada unsur Fe (Nagase dan Kojima, 1997; Govindarao, Pruseth dan Mishra, 2018).

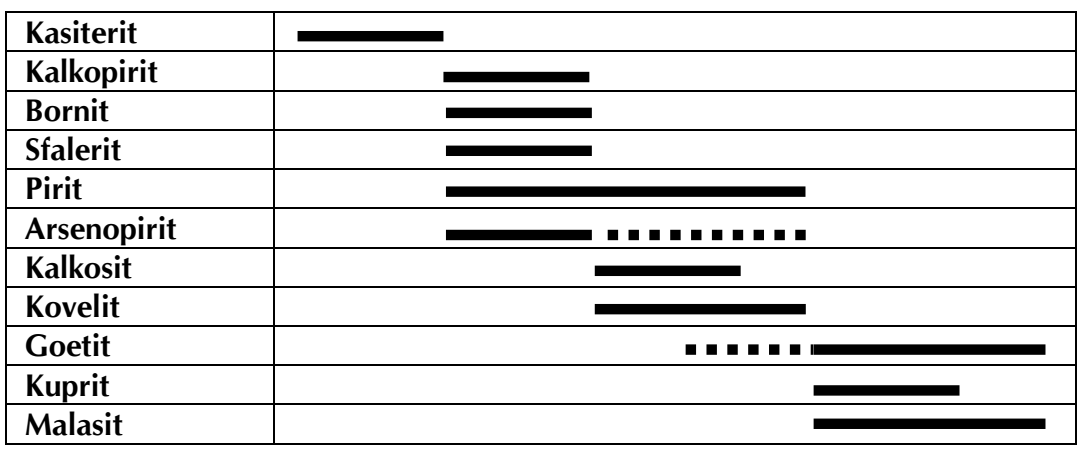

Gambar 6. Paragenesa mineral bijih dari percontoh MGR18M010F 
Yang cukup menarik dari hasil pengukuran geokimia, bahwa hampir di setiap mineral menunjukkan kehadiran unsur Sn dalam jumlah kecil.

\section{KESIMPULAN}

Mineralisasi yang terjadi pada percontoh MGR18M010F didominasi oleh mineralisasi Fe$\mathrm{Cu}$ yang terbentuk dalam 2 tahap, yaitu tahap pembentukan mineral sulfida (bornit-kalkopiritsfalerit-pirit-arsenopirit-kalkosit-kovelit) dan tahap pembentukan mineral oksida (gutit-cupritmalasit). Pada tahapan mineral oksida kemungkinan mineralisasi dikontrol oleh kehadiran urat gutit. Sekuen mineralisasimineralisasi ini memotong mineralisasi kasiterit $\left(\mathrm{SnO}_{2}\right)$ yang sudah terlebih dahulu terbentuk.

Hasil uji geokimia menggunakan AAS diketahui bahwa percontoh ini memiliki nilai kadar $\mathrm{Cu}$ 5,13\%; Pb 0,5 \%; Zn 620 ppm dan Sn 120 ppm, sedangkan hasil pengukuran dengan alat SEMEDS, diinterpretasikan bahwa rumus empiris dari mineral sulfida adalah kalkopirit $\left(\mathrm{Cu}_{0,9} \mathrm{Fe}_{1,02} \mathrm{~S}_{2}\right)$, bornit $\left(\mathrm{Cu}_{4,1} \mathrm{Fe}_{1,29} \mathrm{~S}_{4}\right)$, sfalerit $\left(\left(\mathrm{Zn}_{0,64} \mathrm{Fe}_{0,2}\right) \mathrm{S}_{2}\right)$, pirit $\left(\mathrm{Fe}_{1,01} \mathrm{~S}_{2}\right)$, arsenopirit $\left(\mathrm{Fe}_{1,13} \mathrm{Ass}_{0,62} \mathrm{~S}\right)$, kovelit $\left(\mathrm{Cu}_{1,06 \mathrm{~S}}\right)$ dan kalkolsit $\left(\mathrm{Cu}_{1,58} \mathrm{~S}\right)$. Pada setiap mineral ini ditemukan residual unsur Sn pada setiap senyawanya dalam jumlah yang rendah. Hal ini menunjukkan bahwa kemungkinan larutan pembentukan mineral-mineral sulfida tersebut terasimilasi atau sudah melakukan kontak dengan batuan pembawa unsur Sn seperti yang ditunjukkan pada hasil pengamatan mineragrafi bahwa sekuen mineral sulfida terbentuk setelah kehadiran mineral kasiterit. Pengukuran dengan menggunakan SEM EDS pada sayatan mineral bornit-kalkopirit menunjukkan terjadinya pelepasan unsur Fe dan $\mathrm{S}$ ke arah mineral kovelit-kalkosit, sedangkan pada sayatan mineral sfalerit menunjukkan terjadinya pelepasan unsur $\mathrm{Zn}$ dan $\mathrm{S}$ ke arah mineral kalkosit.

\section{UCAPAN TERIMA KASIH}

Penulis mengucapkan terima kasih kepada Kepala Sub Bidang Mineral Logam Pusat Sumber Daya Mineral Batubara dan Panasbumi serta Laboratorium Fisika Mineral Pusat Penelitian dan Pengembangan Teknologi Mineral dan Batubara atas kebijakan dan fasilitasnya sehingga penelitian ini dapat dilakukan dengan baik dan lancar. Selain itu, terima kasih juga disampaikan kepada rekanrekan Subbidang Mineral Logam khususnya Dr. rer. nat Ernowo atas diskusi, arahan dan masukannya sehingga makalah ini dapat diselesaikan.

\section{DAFTAR PUSTAKA}

Aryanto, N. C. D., Nasrun, N., Sianipar, A. H. dan Sarmili, L. (2016) "Granit Kelumpang sebagai granit tipe-I di pantai Teluk Balok, Belitung," Jurnal Geologi Kelautan, 3(1), hal. 19-27. doi: 10.32693/jgk.3.1.2005.121.

Astuti, T. R. P., Aditiyo, R., Oktavioni, A. dan Supriyanto (2020) "SEM-EDX study on authigenic clay minerals in sandstone of Jatiluhur formation," IOP Conference Series: Earth and Environmental Science, 538, hal. 012041.

doi: 10.1088/1755-1315/538/1/012041.

Baharuddin dan Sidarto (1995) "Systematic geologic map of Indonesia; lembar Belitung, 1212, 1213, 1312, 1313," in Peta Geologi Lembar Belitung, Sumatera. Bandung: Pusat Penelitian dan Pengembangan Geologi, hal. 1.

Barton, N. R. (1978) "Suggested methods for the quantitative description of discontinuities in rock masses: International Society for Rock Mechanics," International Journal of Rock Mechanics and Mining Science \& Geomechanics, 15(6), hal. 319-368.

Batista, A. H., Melo, V. F., Gilkes, R. dan Roberts, M. (2018) "Identification of heavy metals in crystals of sand and silt fractions of soils by scanning electron microscopy (SEM EDS/WDEPMA)," Revista Brasileira de Ciência do Solo, 42, hal. e0170174.

doi: 10.1590/18069657rbcs20170174.

Govindarao, B., Pruseth, K. L. dan Mishra, B. (2018) "Sulfide partial melting and chalcopyrite disease: An experimental study," American Mineralogist, 103(8), hal. 1200-1207. doi: 10.2138/am-2018-6477.

Hafner, B. (2013) "Energy dispersive spectroscopy on the SEM: A primer," in Characterization Facility. Twin Cities: University of Minnesota.

Ikhsan, N. dan Titisari, A. D. (2016) "Mineralogi dan geokimia granitoid Bukit Baginda, Pulau Belitung, Indonesia," in Hidayat, R. et al. (ed.) Proceeding,Seminar Nasional Kebumian Ke-9. 
Yogyakarta: Universitas Gadjah Mada, hal. 469-484.

Johari, S. (1987) "Relationship between Sn mineralization and geochemical anomalies in non-residual overburden at Tebrong area, Belitung, Indonesia," in Thiramongkol, N. (ed.) Proceeding Workshop on Economic geology, Tectonics, Sedimentary Processes and Environment of the Quaternary in Southeast Asia. Bangkok: Chulalongkorn University, hal. 157-172.

Jones, M. T., Reed, B. L., Doe, B. R. dan Lanphere, M. A. (1977) "Age of tin mineralization and plumbotectonics, Belitung, Indonesia," Economic Geology, 72(5), hal. 745-752. doi: 10.2113/gsecongeo.72.5.745.

Kant, W., Warmada, I. W., Idrus, A., Setijadji, L. D. dan Watanabe, K. (2015) "Ore mineralogy and mineral chemistry of pyrite, galena, and sphalerite at soripesa prospect area, Sumbawa Island, Indonesia," Journal of Applied Geology, 4(1), hal. 1-14. doi: 10.22146/jag.7191.

Liu, R., Chen, G. dan Yang, J. (2020) "Compositions of $\mathrm{Cu}$-(Fe)-sulfides in the 109 reduced graniterelated Cu deposit, Xinjiang, Northwest China: Implications to the characteristics of oreforming fluids," Geofluids, 2020, hal. 1-11. doi: 10.1155/2020/7391369.

Miler, M., Curk, U. dan Mirtič, B. (2009) "The use of SEM/EDS method in mineralogical analysis of ordinary chondritic meteorite," Geologija, 52(2), hal. 183-192.

doi: 10.5474/geologija.2009.018.

Nagase, T. dan Kojima, S. (1997) "An SEM examination of the chalcopyrite disease texture and its genetic implications," Mineralogical Magazine, 61(404), hal. 89-97. doi: 10.1180/minmag.1997.061.404.09.
Natasia, N., Barkah, M. N., Saputra, D. H. dan Alfadli, M. K. (2016) "Studi awal potensi bahan galian pada daerah Kabupaten Belitung Timur, Indonesia," Bulletin of Scientific Contribution: Geology, 14(2), hal. 153-162.

Ngadenin, N., Indrastomo, F. D., Karunianto, A. J. dan Rakhma, E. (2017) "Geologi dan identifikasi cebakan bijih di daerah Batubesi, Belitung Timur," EKSPLORIUM, 38(1), hal. 7-18. doi: 10.17146/eksplorium.2017.38.1.3376.

Pardiarto, B. (2016) "Karakteristik cebakan timah primer di daerah Parit Tebu, Kabupaten Belitung Timur, Provinsi Kepulauan Bangka Belitung," Buletin Sumber Daya Geologi, 11(2), hal. 73-91. doi: 10.47599/bsdg.v11i2.11.

Schwartz, M. O. (1992) "Geochemical criteria for distinguishing magmatic and metasomatic albite-enrichment in granitoids? examples from the Ta-Li granite Yichun (China) and the Sn-W deposit Tikus (Indonesia)," Mineralium Deposita, 27(2), hal. 101-108. doi: 10.1007/BF00197092.

Sutarto, Ngadenin, Indrastomo, F. D., Kamajati, D., Rahmawati, P., Oktavian, P. dan Adryanto, P. (2017) "Mineralisasi bijih timah dan thorium di Kabupaten Belitung Timur, Provinsi Kep. Bangka-Belitung," in Widyaningsih, R. (ed.) Prosiding Nasional Kebumian XII. Yogyakarta: Fakultas Teknologi Mineral, Universitas Pembangunan Nasional "Veteran" Yogyakarta, hal. 151-160.

Yahya, A. (2016) Menentukan rumus kimia mineral dan mengeplot ke diagram ternary, http://www.andyyahya.com. Tersedia pada: http://www.andyyahya.com/2015/08/menent ukan-rumus-kimia-mineral.html (Diakses: 17 Agustus 2020). 